\title{
Aggravated Epilepsy
}

National Cancer Institute

\section{Source}

National Cancer Institute. Aggravated Epilepsy. NCI Thesaurus. Code C8598.

An increase in the duration or intensity of epileptic symptoms in the setting of chronic epilepsy. 